\title{
Los consorcios y la problemática del personal a su servicio
}

\section{The consortia and his staff problems}

\author{
Javier Eduardo Quesada Lumbreras \\ Universidad de Granada \\ jaque@ugr.es
}

\section{NOTA BIOGRÁFICA}

Profesor de Derecho Administrativo de la Universidad de Granada. Doctor en Derecho. Ha impartido cursos y seminarios en diferentes Universidades nacionales y extranjeras así como en otros Institutos de formación. Sus líneas de investigación se centran en las materias de empleo público, gobierno local, organización administrativa y Principios Generales del Derecho.

\section{RESUMEN}

En este trabajo voy a analizar el régimen jurídico de los consorcios. Una figura que, en los últimos años, ha experimentado una atención normativa sin precedentes. Su régimen orgánico, funcional, presupuestario y de gestión de personal se ha intensificado notablemente. El objetivo de las últimas reformas ha sido muy loable y comprensible tras todos estos años de crisis económica que seguimos padeciendo. Pero creo que las medidas normativas que han sido adoptadas se han cebado en exceso en torno a esta figura que no hace sino dar cumplimiento a uno de los principios más esenciales de nuestro Estado de Derecho. Y no sólo eso sino que además, en la materia que centraré especialmente mi atención, se ha generado más incertidumbre que seguridad y certeza jurídica a nuestros operadores jurídicos.

\section{PALABRAS CLAVE}

Consorcios; empleados públicos; necesidades de reforma.

\begin{abstract}
In this paper i will analyze the legal regime of consortia. A institution that, in recent years, has experienced unprecedented regulatory attention. Its organic, functional, budgetary and staff management regime has intensified notably. The objective of the last reforms has been very laudable and understandable after all these years of economic crisis that we continue to suffer. But i believe that the normative measures adopted have injures this institution which is essential in our State of Law. And not only that, but also, in the subject that will focus my attention especially, has generated more uncertainty than security and legal to our legal operators.
\end{abstract}

\section{KEYWORDS}

Consortia; civil servant; needs for reform.

\section{SUMARIO}

I. CONFIGURACIÓN JURÍDICA DE LA FIGURA: EVOLUCIÓN Y SITUACIÓN ACTUAL. 1. LA LEGISLACIÓN LOCAL Y LAS BASES DEL RÉGIMEN JURÍDICO DE LAS ADMINISTRACIONES PÚBLICAS. 2. UN CAMBIO DE RUMBO: LA RACIONALIZACIÓN DEL SECTOR PÚBLICO Y LAS NUEVAS LEYES ADMINISTRATIVAS. II. PROBLEMÁTICA DE SU RÉGIMEN JURÍDICO: ESPECIAL REFERENCIA A LA GESTIÓN DE PERSONAL. 1. RÉGIMEN JURÍDICO DEL PERSONAL AL SERVICIO DE LOS CONSORCIOS. 
2. CLASES DE PERSONAL. 3. SELECCIÓN, PROVISIÓN DE PUESTOS DE TRABAJO Y MOVILIDAD DE PERSONAL. 4. CAMBIO DE ADSCRIPCIÓN Y DISOLUCIÓN DEL CONSORCIO: INCIDENCIA EN EL PERSONAL A SU SERVICIO. III. CONCLUSIONES. IV. BIBLIOGRAFÍA.

\section{CONFIGURACIÓN JURÍDICA DE LA FIGURA: EVOLUCIÓN Y SITUACIÓN ACTUAL}

\section{La legislación local y las bases del régimen jurídico de las Administraciones Públicas}

El régimen jurídico de los consorcios ha experimentado, especialmente en los últimos años, una modificación sustancial en los contornos básicos que han caracterizado tradicionalmente a esta figura ${ }^{1}$. Sus principales características podrían sintetizarse en las siguientes ideas:

1. ${ }^{a}$ Se trata de un instrumento de cooperación que disponen las Entidades Locales, y ya sea entre Entidades Locales exclusivamente o entre éstas y la Administración autonómica respectiva, la Administración General del Estado o, inclusive, con entidades privadas sin ánimo de lucro. Por tanto, estamos en presencia de una figura de carácter asociativo y voluntario cuya iniciativa corresponde a la Administración Local.

2. ${ }^{a} \quad$ La finalidad de esta asociación debe ser la ejecución o gestión de intereses públicos concurrentes entre los entes asociados.

3. ${ }^{a} \quad$ La asociación de entes consorciados adquiere personalidad jurídica y serán sus Estatutos los que determinen las particularidades del régimen orgánico, funcional y financiero.

4. ${ }^{a} \quad$ La gestión de los servicios concurrentes, ya sea directa o indirecta, sustituirá a los entes consorciados.

5. ${ }^{a}$ Sus órganos de decisión estarán integrados por representantes de todas las entidades consorciadas, en la proporción que se fije en los Estatutos respectivos.

Esta caracterización que se deriva de la normativa estatal será objeto, en algunos casos como señala BARRERO RODRÍGUEZ, «de complemento por el ordenamiento autonómico del que, con carácter general, puede afirmarse, no obstante, su clara opción en favor de la determinación del régimen del consorcio en los propios estatutos de cada una de las entidades creadas».

El consorcio, de esta forma, prolifera extraordinariamente y se consolida a juicio de la autora «como una entidad absolutamente versátil, dada, de una parte, las amplias posibilidades que ofrece en su propia composición subjetiva y, de otra, su adscripción al servicio de lo más diversos fines. Los consorcios se convierten así en una entidad que vale tanto para prestar servicios municipales básicos como para el desarrollo de objetivos diferentes que exceden del ámbito específico de la competencia municipal por implicar a las de otras instancias; una fórmula idónea para la satisfacción de un objetivo coyuntural, pero, también, una entidad válida para el desempeño de cometidos permanentes en el tiempo» ${ }^{2}$.

Este crecimiento desorbitado de los consorcios va provocar una reacción, tanto a nivel estatal como autonómico, para ejercer un control esencialmente en el ámbito económico-financiero dando cumplimiento así a los objetivos de estabilidad presupuestaria. La Ley 47/2003, de 26 de noviembre, General Presupuestaria, dirigida a delimitar el sector público estatal y sus entes integrantes (el consorcio entre ellos) y, muy especialmente, su control económico-financiero ${ }^{3}$; y, el Real Decreto Legislativo 2/2007, de 28 de diciembre,

\footnotetext{
1 Este trabajo se realiza en el marco del Proyecto de Investigación del Instituto Nacional de Administración Pública Público y Privado en la gestión de los servicios públicos: reestructuración, externalización y reversión a la Administración.

2 BARRERO RODRÍGUEZ, C., "Los consorcios ante un nuevo régimen jurídico", Administración de Andalucía. Revista Andaluza de Administración Pública, núm. 94, enero-abril 2016, pág. 60. La proliferación extraordinaria de los consorcios puede comprobarse, como añade la autora, "entre otros documentos, en los datos ofrecidos por el "Informe trimestral de seguimiento de las medidas de la Comisión para la Reforma de las Administraciones Públicas" de la "Oficina para la ejecución de la reforma de la Administración" correspondiente al $3 .^{\circ}$ trimestre de 2015, que señala que "entre 2005 y 2011, el número de empresas, fundaciones y consorcios públicos pasó de 3.228 a 4.036. Es decir, se crearon 808, y ello en los ejercicios de mayor incidencia de la crisis financiera y presupuestaria"».

3 Igualmente en el ámbito autonómico podemos encontrar normas presupuestarias y financieras dirigidas al mismo propósito: Decreto Legislativo 1/2000, de 29 de junio por el que se aprueba el Texto Refundido de la Ley de Hacienda Foral de la Comunidad Autónoma de Aragón; Ley 14/2006, de 24 de octubre de Finanzas de Cantabria; Ley 2/2006, de 3 de mayo de Hacienda y del Sector Público de Castilla y León; Ley 11/2006, de 11 de diciembre de Hacienda de Canarias; Ley 5/2007, de 19 de abril, de Hacienda de Extremadura; o, por poner un último ejemplo, el Decreto Legislativo 1/2010, de 2 de marzo, por el que se aprueba el Texto Refundido de la Ley General de Hacienda Pública de la Comunidad Autónoma de Andalucía.

Esta necesidad de delimitar los requisitos de adscripción de los consorcios también se extiende en el ámbito autonómico a través de la legislación local, reconociendo incluso al consorcio como una entidad local: Ley 5/1997, de 22 de julio, de Administración Local
} 
por el que se aprueba el Texto Refundido de la Ley General de Estabilidad Presupuestaria, van a constituir dos buenos ejemplos en esta dirección.

\section{Un cambio de rumbo: la racionalización del sector público y las nuevas leyes administrativas}

La crisis económica iniciada en el año 2008 y que provocará, entre otros efectos evidentes que aun perduran, la entrada anticipada de un nuevo Gobierno de la Nación en las elecciones de diciembre de 2011, harán centrar la atención del legislador en la reforma de las Administraciones Públicas y especialmente en el «adelgazamiento» de las diferentes organizaciones públicas que conforman el sector público.

El Informe de la Comisión para la Reforma de las Administraciones Públicas constituye, sin duda alguna, un punto de inflexión en la materia. El objetivo de este Informe era realizar un estudio integral en la temática que permitiera concretar un conjunto de propuestas en línea con los ejes de acción marcados en el Plan Nacional de Reformas 2012 y orientadas fundamentalmente, en consecuencia, a seguir conteniendo el gasto público como vía prioritaria para reducir el déficit público.

Del elenco de reformas aprobadas hasta la fecha como consecuencia de las medidas propuestas en el Informe, tres nuevas leyes destacan especialmente y marcarán un cambio de rumbo en la configuración jurídica de los consorcios, a saber 4 : la Ley 27/2013, de 27 de diciembre, de Racionalización y Sostenibilidad de la Administración Local (LRSAL, en adelante); la Ley 15/2014, de 16 de septiembre, de Racionalización del Sector Público y otras medidas de reforma administrativa (LRSP, en adelante); y, Ley 40/2015, de 1 de octubre, de Régimen Jurídico del Sector Público (LRJSP, en adelante). Los ejes fundamentales del nuevo cambio de rumbo pueden sintetizarse en las siguientes ideas.

La LRSAL viene a adicionar la regulación básica de los consorcios a través de varias Disposiciones. En primer lugar, y bajo la denominación de "Consorcios constituidos para la prestación de servicios mínimos», la Disposición Adicional Decimotercera establece que el personal al servicio de los consorcios públicos constituidos hasta su entrada en vigor que presten servicios mínimos podrá integrarse por quienes no sean personal funcionario o laboral procedente de una reasignación de puestos de trabajo de las Administraciones participantes en el consorcio ${ }^{5}$.

En segundo lugar, y a través de su Disposición Final Segunda, establece una nueva redacción a la Disposición Adicional Vigésima de la LRJPAC introduciendo el nuevo régimen jurídico de los consorcios conforme a las siguientes reglas básicas:

1. ${ }^{a}$ Los Estatutos de cada consorcio determinarán, en cada ejercicio presupuestario y por todo este periodo, la Administración Pública a la que estará adscrito, así como su régimen orgánico, funcional y financiero.

2. ${ }^{a} \quad$ Los criterios de prioridad que determinan qué Administración Pública es a la que está adscrito el consorcio ${ }^{6}$.

de Galicia; Ley 20/2006, de 15 de diciembre, municipal y de régimen local de las Illes Balears; y, la Ley 5/2010, de 11 de junio, de autonomía local de Andalucía.

En otras ocasiones también, las menos como señala FERREIRA FERNÁNDEZ ("Los consorcios del sector público autonómico: naturaleza y características”, Revista de Estudios de la Administración Local y Autonómica, núm. 310, 2009, pág. 184): «serán las normas reguladoras de la Administración Pública autonómica las que determinen esta adscripción, considerando de aplicación a los consorcios integrados en el sector público autonómico el ordenamiento jurídico propio de la Comunidad Autónoma de que se trate. Es el caso de las Leyes 3/2003, de 26 de marzo, de Régimen de la Administración de las Islas Baleares, 15/2004, de 3 de diciembre, de la Administración Foral de Navarra o 9/2007, de 22 de octubre, de Administración de la Junta de Andalucía».

4 Igualmente destacables, por su incidencia en las relaciones laborales del sector público, serían el Real Decreto-Ley 3/2012, de 10 de febrero, de medidas urgentes para la reforma del mercado laboral, y la posterior la Ley 3/2012, de 6 de julio, así como el Real Decreto 1483/2012, de 29 de octubre que aprueba el Reglamento de los procedimientos de despido colectivo y de suspensión de contratos y reducción de jornada, cuyo ámbito de aplicación (Administraciones Públicas del art. 3.2 de la Ley 9/2017, de 8 de noviembre, de Contratos del Sector Público) se extiende también a los consorcios.

5 En este punto, cabe subrayar que la Sentencia 111/2016, de 9 de junio de 2016, ante el Recurso de inconstitucionalidad interpuesto por el Consejo de Gobierno de la Junta de Andalucía en relación con diversos preceptos de la LRSAL, ha declarado inconstitucionales y nulos los incisos de este art. 26 LBRL que hacia referencia «al Ministerio de Hacienda y Administraciones Públicas» y «Para reducir los costes efectivos de los servicios el mencionado Ministerio decidirá sobre la propuesta formulada que deberá contar con el informe preceptivo de la Comunidad Autónoma si es la Administración que ejerce la tutela financiera».

6 Llama especialmente la atención, como advierte BASSOLS COMA ("La racionalización de la Administración local en el marco de la sostenibilidad financiera: panorama general”, Cuadernos de Derecho Local, núm. 34, Fundación Democracia y Gobierno Local, Madrid, 2014, pág. 36) que: «La singularidad de este régimen jurídico estriba precisamente en situar y encuadrar la adscripción de estos consorcios, para lo que se fija una enumeración prioritaria o preferente de siete criterios de adscripción (figurando en primer lugar el de 
3. ${ }^{a}$ Los consorcios estarán sujetos al régimen de presupuestación, contabilidad y control de la Administración Pública a la que estén adscritos. El órgano de control de esta Administración será el responsable de llevar una auditoría de las cuentas anuales.

4. ${ }^{a} \quad$ Los consorcios deberán formar parte de los presupuestos e incluirse en la cuenta general de la Administración Pública de adscripción.

5. ${ }^{a}$ El régimen jurídico del personal al servicio de los consorcios será el de la Administración Pública de adscripción y sus retribuciones en ningún caso podrán superar las establecidas para puestos de trabajo equivalentes en aquélla?

En consecuencia, los consorcios que cumplan todos y cada uno de los requisitos reseñados se regirán por las previsiones establecidas en sus respectivos Estatutos. Aquéllos que no lo cumplan deberán ajustar sus Estatutos al nuevo régimen que se deriva de la LRSAL ${ }^{8}$.

El marco jurídico de los consorcios establecido por la LRSAL, aplicable a cualquier consorcio con independencia de su dimensión estatal, autonómica o local, no termina aquí. Y es que, en efecto, no podemos perder de vista las exigencias dirigidas específicamente a los consorcios locales contenidas en la nueva redacción del art. 57 LBRL.

La incidencia más directa que se deriva de este precepto es que la constitución de un consorcio a iniciativa de una Entidad Local tendrá carácter subsidiario. Sólo podrá tener lugar cuando la cooperación económica, técnica y administrativa entre la Administración Local y la Administración del Estado o la Comunidad Autónoma no pueda formalizarse a través de un convenio y siempre que, en términos de eficiencia económica, aquélla permita una asignación más eficiente de los recursos económicos.

Además, tiene que constatarse que la constitución del consorcio no pone en riesgo la sostenibilidad financiera de la Entidad Local y del propio consorcio, el cual no podrá demandar más recursos de los inicialmente previstos. Y todo ello teniendo en cuenta, además, que la constitución del consorcio ha de mejorar la eficiencia de la gestión pública, eliminar duplicidades administrativas y cumplir con la legislación de estabilidad presupuestaria y sostenibilidad financiera (art. 57. 2 y 3 LBRL).

Este precepto, a mi juicio, condiciona de forma muy acentuada la posibilidad de crear consorcios a iniciativa de la Administración Local y presenta serias dudas de constitucionalidad por lo que a la potestad de autoorganización local y a las competencias sobre régimen local que tienen atribuidas las Comunidades Autónomas se refiere. La realidad, sin embargo, es que el art. 57 LBRL ha sido avalado por el Tribunal Constitucional en su Sentencia 41/2016, de 3 de marzo; dando preferencia así a los criterios de racionalidad económica, estabilidad presupuestaria y sostenibilidad financiera ${ }^{9}$.

la mayoría de votos en el órgano de gobierno, pero siendo el último en relevancia nada menos que el de mayor número de habitantes y extensión territorial, cuando el consorcio está orientado a la prestación de servicios a las personas o al desarrollo de la actuación sobre el territorio)».

7 Se establece, no obstante, un régimen especial para determinados consorcios a los que no será de aplicación las reglas básicas señaladas anteriormente. Así conforme a la Disposición Adicional Decimocuarta de la LRSAL el nuevo régimen jurídico básico no afectará a aquellos consorcios que cumplan los siguientes requisitos: 1) Que estén constituidos antes de la entrada en vigor de la LRSAL. 2) No tengan la consideración de Administración Pública a efectos del Sistema Europeo de Cuentas. 3) Estén participados por Entidades Locales y entidades privadas. 4) No estén incursos en pérdidas durante dos ejercicios consecutivos y no reciban ni hayan recibido subvenciones de las Administraciones Públicas en los cinco ejercicios anteriores al de entrada en vigor de la LRSAL, con independencia de las aportaciones a las que estén obligados los entes consorciados.

8 Ciertamente, la adaptación no va a ser sencilla y por ello se ha previsto un régimen transitorio especialmente dirigida aquellos consorcios que se hayan creado en el momento de entrada en vigor de la LRSAL (el 30 de diciembre de 2013). Este régimen jurídico viene establecido en la Disposición Transitoria Sexta y como puede deducirse se trata de una adaptación a la nueva normativa básica de los consorcios dilatada en el tiempo. Así estos consorcios deberán adaptar sus Estatutos al nuevo régimen jurídico en el plazo de un año desde la entrada en vigor de la LRSAL (hasta el 31 de diciembre de 2014). No obstante, si esta adaptación diera lugar a un cambio en el régimen jurídico aplicable al personal a su servicio o en su régimen presupuestario, contable o de control, este nuevo régimen será de aplicación a partir del 1 de enero del año siguiente (hasta el 1 de enero de 2016).

9 Como establece la Sentencia, que resuelve el recurso de inconstitucionalidad interpuesto por la Asamblea de Extremadura, en su Fundamento Jurídico 8. ${ }^{\circ}$ :

«Las técnicas organizativas y los instrumentos de cooperación forman parte, de entrada, de la potestad de autoorganización local y de las competencias sobre régimen local que tienen atribuidas las Comunidades Autónomas. No obstante, al reseñar la doctrina constitucional (FJ 5 de esta Sentencia), hemos razonado igualmente que el art. 149.1.18 CE puede dar cobertura a una legislación básica estatal que incida sobre los entes locales con autonomía constitucionalmente garantizada, que proyecte los principios de eficacia, eficiencia y estabilidad presupuestaria sobre el régimen local o que articule una ordenación básica de las relaciones interadministrativas de cooperación. Las mancomunidades y los consorcios no son ajenos a ninguno de estos aspectos: 1) sus intereses son los de los entes locales mancomunados o consorciados; 2) su régimen de constitución, funcionamiento y funciones es evidentemente relevante bajo la óptica de la racionalidad del gasto público; 3) son instrumentos fundamentales para la "gestión compartida" (art. 26.2 LRBRL) 
Otra exigencia dirigida específicamente al ámbito local se contiene en la nueva redacción de la Disposición Adicional Novena LBRL introducida por la LRSAL que, bajo la denominación de «Redimensionamiento del sector público local», prohíbe que las Entidades Locales (y sus organismos autónomos) puedan adquirir, constituir o participar en la constitución, directa o indirectamente, de nuevos consorcios durante el tiempo de vigencia de su plan económico-financiero o de su plan de ajuste. Planteándose incluso, para los ya existentes, su disolución si no se encuentran en situación de superávit, equilibrio o no tienen resultados positivos de explotación.

Todo este marco jurídico de la LRSAL se verá complementado con la $\operatorname{LRSP}^{10}$, en la que se regula las causas y procedimiento para el ejercicio del derecho de separación de un consorcio, los efectos del ejercicio del derecho de separación, el régimen de liquidación del consorcio así como el plazo de adaptación de estatutos y derecho supletorio (arts. 12 a 15 LRSP).

La LRJSP, finalmente, elevará a los consorcios a las nuevas bases del régimen jurídico del sector público (arts. 118 a 127 LRJSP), constituyéndose así como la normativa de cabecera en la materia al atribuirle expresamente el carácter de supletorio a las normas contenidas en la LBRL y a las introducidas por la LRSAL.

Bajo este marco jurídico básico de la LRJSP se define a los consorcios como «entidades de derecho público, con personalidad jurídica propia y diferenciada, creadas por varias Administraciones Públicas o entidades integrantes del sector público institucional, entre sí o con participación de entidades privadas, para el desarrollo de actividades de interés común a todas ellas dentro del ámbito de sus competencias», estableciéndose como actividades propias de los mismos «las actividades de fomento, prestacionales o de gestión común de servicios públicos y cuantas otras estén previstas en las leyes».

Se crean mediante convenio suscrito por las Administraciones, organismos públicos o entidades participantes (art. 123. 1 LRJSP). Y son los Estatutos de cada consorcio los que determinan la Administración a la que está adscrito, en cada ejercicio presupuestario y por todo ese periodo, de acuerdo con los criterios establecidos en el art. 120.2 LRJSP ${ }^{11}$.

en el contexto de un Estado compuesto, en general, y de un mapa local caracterizado por la proliferación de municipios pequeños, en particular».

A juicio del Alto Tribunal, el art. 57 LBRL remite «el régimen de las fórmulas de cooperación a "los términos previstos en las leyes" (apartado 1), sin incluir una regulación completa del consorcio que pudiera desbordar la competencia estatal para fijar las bases del régimen local. Introduce solo algunos límites a la constitución y funcionamiento del consorcio que, con independencia de su eficacia real, están claramente destinados a introducir los criterios de racionalidad económica que exige la realización de mandatos constitucionales (arts. 31.2, 103.1, 135, 137, $140 \mathrm{CE}$ ).

Ningún problema de constitucionalidad puede suscitar la previsión genérica de que el consorcio, sin poner en riesgo la sostenibilidad financiera del conjunto de la Hacienda de la Entidad Local, debe permitir "una asignación más eficiente de los recursos económicos" y mejorar la eficiencia de la gestión pública, eliminar duplicidades administrativas y cumplir con la legislación de estabilidad presupuestaria y sostenibilidad financiera (apartados 2 y 3 ).

La preferencia asignada a la fórmula convencional en detrimento de la consorcial (apartado 3) puede discutirse políticamente, pero constituye una directriz directamente encaminada a desarrollar una política de contención de personificaciones públicas que se sitúa dentro de los amplios márgenes de configuración legislativa que abre la Constitución y amparan los apartados 14 y 18 del art. 149.1 CE. Lo mismo cabe decir de la previsión de que los consorcios constituidos no podrán demandar más recursos de los inicialmente previstos (apartado 3)».

10 Así la nueva regulación de los consorcios administrativos, establecida por la LRSAL y la Ley 15/2014, se caracteriza, como expresa TOSCANO GIL ("El consorcio administrativo en la encrucijada", Revista de Estudios de la Administración Local y Autonómica. Nueva Época, núm. 3, enero-junio, 2015 pág. 21): «por un incremento de la heterorregulación de su régimen jurídico, que deja menos sitio a la autorregulación por las entidades consorciadas mediante sus estatutos, especialmente, la primera, en bastante menor medida, la segunda. En la medida en que esta heterorregulación se hace a través de normas estatales básicas, no solo se deja menos espacio a la autorregulación por las entidades consorciadas, sino también a la heterorregulación por las Comunidades Autónomas con competencias en la materia».

11 Los criterios son los siguientes: 1) La que disponga de la mayoría de votos en los órganos de gobierno. 2) La que tenga facultades para nombrar o destituir a la mayoría de los miembros de los órganos ejecutivos. 3) La que tenga facultades para nombrar o destituir a la mayoría de los miembros del personal directivo. 4) La que disponga de un mayor control sobre la actividad del consorcio debido a una normativa especial. 5) La que tenga facultades para nombrar o destituir a la mayoría de los miembros del órgano de gobierno. 6) La que financie en más de un cincuenta por ciento, en su defecto, en mayor medida la actividad desarrollada por el consorcio, teniendo en cuenta tanto la aportación del fondo patrimonial como la financiación concedida cada año. 7) La que ostente el mayor porcentaje de participación en el fondo patrimonial. 8) La que tenga mayor número de habitantes o extensión territorial dependiendo de si los fines definidos en el estatuto están orientados a la prestación de servicios a las personas, o al desarrollo de actuaciones sobre el territorio.

Es importante subrayar que actualmente está pendiente de resolución un recurso de inconstitucionalidad contra este art. 120. 2 LRJSP. Efectivamente, el Pleno del Tribunal Constitucional, por Providencia de 19 de julio de 2016, admitió a trámite el recurso de inconstitucionalidad núm. 3774-2016, contra los artículos 39; 49 h), párrafo segundo, y por conexión, la Disposición Adicional Octava, 1; 52.2 desde «teniendo en cuenta» hasta el final del apartado; 81.3; 83.2.c y, por conexión, la Disposición Adicional Octava, 2; 120.2 ; 121; 122; 126; 129.2; 157.3, último párrafo, y por conexión con los citados preceptos, la Disposición Final Decimocuarta de la LRJSP. 
En los supuestos en que participen entidades privadas, el consorcio no tendrá ánimo de lucro y estará adscrito a la Administración Pública que corresponda en función de los criterios señalados ${ }^{12}$. Asimismo, cualquier cambio de adscripción a una Administración Pública, cualquiera que fuere su causa, conllevará la modificación de los estatutos del consorcio en un plazo no superior a seis meses, contados desde el inicio del ejercicio presupuestario siguiente a aquel en se produjo el cambio de adscripción (arts. 120. 3 y 4 LRJSP) ${ }^{13}$.

Esta es, en la actualidad, la configuración jurídica de los consorcios locales, autonómicos y estatales ${ }^{14}$. Me corresponde ahora profundizar un poco más en la materia aunque no en su globalidad, ya que se excedería de la pretensión de este trabajo, sino que me centraré en la específica problemática que se plantea en la gestión del personal a su servicio.

\section{PROBLEMÁTICA DE SU RÉGIMEN JURÍDICO: ESPECIAL REFERENCIA A LA GESTIÓN DE PERSONAL}

\section{Régimen jurídico del personal al servicio de los consorcios}

El régimen jurídico del personal al servicio de los consorcios, conforme al art. 121 LRJSP, está constituido por las siguientes notas básicas:

- El personal al servicio de los consorcios podrá ser funcionario o laboral y habrá de proceder exclusivamente de las Administraciones participantes. Si no fuera posible contar con personal procedente de estas Administraciones se podrá contratar personal directamente por parte del consorcio, con carácter excepcional y para el ejercicio de las funciones que no se pueden cubrir ${ }^{15}$.

- Su régimen jurídico será el de la Administración Pública de adscripción y sus retribuciones en ningún caso podrán superar las establecidas para puestos de trabajo equivalentes en aquélla.

${ }^{12}$ Como señala GARCíA RUBIO, F., "Los consorcios locales en el Proyecto de Ley de Régimen Jurídico del Sector Público. Reflexiones necesarias", Documentación Administrativa. Nueva Época, núm. 2, enero-diciembre 2015, pág. 17: "Esta circunstancia de empresas privadas integrantes de consorcios sin ánimo de lucro puede generar problemas de colisión con otras empresas y con la selección de los integrantes fácilmente evitables con el mantenimiento del régimen actual, o con la incorporación al exhaustivo régimen jurídico básico de los consorcios de unas reglas de selección de las entidades privadas que tengan ánimo de lucro».

13 A juicio de JIMÉNEZ ASENSIO, R. "El sector público local tras la Ley 40/2015: retos inmediatos y cuestiones abiertas", Blog de Estudio de Consultoría Sector Público S.L.U., edición de 17 de julio de 2015, nos encontramos con: «Una regulación de los Consorcios contradictoria: "puente de plata" para abandonar el Consorcio e impulso de nuevos tipos de fórmulas consorciales. Como ya hiciera la Ley 15/2014, de racionalización del sector público, la LRJSP vuelve a tender "puentes de plata", para que las entidades que formen parte del Consorcio huyan del mismo y se busque así la desaparición de tales entidades por abandono de sus miembros. Pero a esa regulación ya existente (ahora reproducida en el artículo 125 de la Ley), se le une la Disposición Adicional Décima de ese mismo texto legal, que "anima" (mediante una exención de sus correspondientes obligaciones) a las entidades que formen parte de un Consorcio a no abonar sus aportaciones al fondo patrimonial o a la financiación comprometida a realizar, siempre que "alguno de los demás miembros del Consorcio no hubieran realizado la totalidad de sus aportaciones dinerarias correspondientes a ejercicios anteriores a las que estén obligados". Curiosa forma de "reventar" los Consorcios a través de "dinamita" legal».

14 Para CASTILLO BLANCO ("La incidencia de la nueva Ley de Régimen Jurídico del Sector Público en los instrumentos de cooperación del Estado Autonómico: especial referencia a los consorcios públicos", Diario del Derecho Municipal. IUSTEL, edición de 10 de marzo de 2017), la LRJSP «deja meridianamente claras dos cosas respecto de la naturaleza jurídica del consorcio (art.118.1), a saber:

- Los Consorcios son una Administración Pública (lo que resulta determinante para su régimen jurídico), pero tiene una naturaleza mixta: de un lado, y dado las funciones que desarrolla, es un ente instrumental de otros pero enclavado en la orbita institucional de la entidad a la que está adscrito; de otro, es un ente asociativo dado que en el mismo se agrupan varias Administraciones Públicas.

- Se refuerza su consideración de ente inserto en el entramado institucional de la Administración a la que se adscribe, en menoscabo de lo asociativo a pesar de que, como expresamente señala el texto normativo, se constituyen para el desarrollo de actividades comunes.

- En el caso de las EELL, y conjugando esta regulación con la de régimen local, es un instrumento de cooperación subsidiario de otras fórmulas de cooperación interadministrativa.

En suma, y desde mi punto de vista, una regulación desafortunada en lo que se refiere al necesario encaje de la figura dentro del principio de cooperación básico en nuestro Estado Autonómico que, como única virtud bien es cierto que no es menor, ha venido a colmar el vacío normativo que presentaba la regulación de la institución consorcial con carácter básico».

15 Efectivamente, como expresa el segundo párrafo del precepto: «Excepcionalmente, cuando no resulte posible contar con personal procedente de las Administraciones participantes en el consorcio en atención a la singularidad de las funciones a desempeñar, el Ministerio de Hacienda y Administraciones Públicas, u órgano competente de la Administración a la que se adscriba el consorcio, podrá autorizar la contratación directa de personal por parte del consorcio para el ejercicio de dichas funciones».

Este precepto (art. 121 LRJSP) tiene pendiente la resolución un recurso de inconstitucionalidad como apuntamos anteriormente (Providencia de 19 de julio de 2016, del Pleno del Tribunal Constitucional, por la que se admite el recurso de inconstitucionalidad núm. 3774-2016). 
Estas notas de carácter básico deben ser complementadas por la normativa básica, de carácter específico, que regula el régimen jurídico de los empleados públicos, esto es, el Real Decreto Legislativo 5/2015, de 30 de octubre, por el que se aprueba el Texto Refundido de la Ley del Estatuto Básico del Empleado Público (EBEP, en adelante), como así se deriva expresamente del art. 2.1 EBEP.

Ambas normas, en consecuencia, son las que han de guiar el análisis del régimen jurídico del personal de los consorcios. Y específicamente, para el personal laboral, además el Real Decreto Legislativo 2/2015, de 23 de octubre, por el que se aprueba el Texto Refundido de la Ley del Estatuto de los Trabajadores (ET, en adelante) y por las demás normas convencionalmente aplicables cuando así lo disponga expresamente el EBEP (art. 7 EBEP).

El análisis, sin embargo, no es tan sencillo y han de tenerse en cuenta también otras normas de carácter presupuestario que vienen a establecer limitaciones para este colectivo. Me refiero, efectivamente, a los Presupuestos Generales del Estado que, con carácter anual aunque no necesariamente ha sido así durante los últimos años, han venido recogiendo determinaciones específicas en la materia.

Así la Ley 6/2018, de 3 de julio, de Presupuestos Generales del Estado para el año 2018 (LPGE de 2018, en adelante) establece las siguientes limitaciones conforme a los arts. 149.1.13. a y $156.1 \mathrm{CE}^{16}$ :

- Aquellos consorcios que pueden contratar personal propio pueden realizar contratos indefinidos con un límite del 75 por ciento de su tasa de reposición salvo para los consorcios que gestionen servicios públicos o realicen actividades específicas (educación, sanidad, asesoramiento jurídico y gestión de recursos públicos, servicios sociales, transporte público, etc. $)^{17}$.

- Queda prohibida la contratación de personal temporal, excepto en casos excepcionales y para cubrir necesidades urgentes e inaplazables.

No obstante, para el conjunto de consorcios locales, tanto los exentos del régimen LRSAL como a los que sí es de aplicación, hay que tener en cuenta asimismo las siguientes limitaciones relativas a:

- La masa salarial del personal laboral del sector público (art. 103 bis LBRL).

- La dotación de personal eventual (art. 104 bis LBRL), cuya versión original de este precepto (apartados 3 y 4) llegaba a prohibir que las plantillas de los consorcios pudieran incluir puestos de trabajo cuya cobertura corresponda a personal eventual y que han sido declarados inconstitucionales y nulos por la STC 54/2017, de 11 de mayo.

- Las retribuciones en los contratos mercantiles y de alta dirección del sector público local y número máximo de miembros de los órganos de gobierno (Disposición Adicional Duodécima LBRL).

Todo este entramado normativo, en suma, constituye el régimen jurídico del personal al servicio de los consorcios. Una amplia regulación que no impide la problemática jurídica y los variados interrogantes que se derivan de la misma.

En este contexto, y a la hora de abordar las principales consecuencias jurídicas que se derivan de la normativa subrayada anteriormente, hay que partir de la base de que nos encontramos en la actualidad con «tres tipos de consorcios», o de consorcios con distinta normativa de referencia si se prefiere denominar así.

$Y$ es que, en efecto, las Disposiciones de la LBRL y de la LRSAL tienen carácter supletorio en todo aquello que no disponga la LRJSP. Y, como veremos, en materia de personal hay determinados aspectos que no aborda expresamente la LRJSP (por ejemplo en materia de selección y provisión de puestos de trabajo).

16 La LPGE de 2018 contiene limitaciones de idéntico tenor literal que las contenidas en la Ley 3/2017, de 27 de junio, de Presupuestos Generales del Estado para el año 2017. Y en la línea que ya impulsara, aunque con importantes matices, la Ley 48/2015, de 29 de octubre, de Presupuestos Generales del Estado para el año 2016 y de la Ley 36/2014, de 26 de diciembre, de Presupuestos Generales del Estado para el año 2015, para la contratación de personal de los consorcios del sector público.

17 Como señala la Disposición Adicional Trigésima Primera («Contratación de personal de los consorcios del sector público»), en el apartado 2: «Los consorcios participados mayoritariamente por las Administraciones y organismos que integran el sector público, definido en el artículo 18, apartado Uno, que, con arreglo a la legislación aplicable puedan contratar personal propio no incluidos en el punto anterior, podrán realizar contratos indefinidos con un límite del 75 por ciento de su tasa de reposición, calculada conforme a las reglas del artículo 19.Uno.7.». Adicionalmente, como establece en su apartado 4, «los consorcios podrán formalizar contratos indefinidos en un número equivalente al 5 por ciento del total de su tasa de reposición, que irán destinados a aquellos sectores o ámbitos que consideren que requieren un refuerzo adicional de efectivos.

Este porcentaje adicional se utilizará preferentemente en sectores con la consideración de prioritarios y cuando se dé, entre otras, alguna de las siguientes circunstancias: establecimiento de nuevos servicios públicos, incremento de actividad estacional por la actividad turística o alto volumen de jubilaciones esperadas». 
Así las consecuencias jurídicas que se derivan del régimen de personal de los consorcios serán distintas en función del tipo de consorcio ante el que nos encontremos.

En primer lugar, podemos encontrarnos consorcios constituidos antes de la entrada en vigor de la LRSAL y que han tenido que adaptar sus Estatutos al régimen establecido en aquélla, siendo de aplicación las Disposiciones de la LRJSP y supletoriamente la LRSAL, adquiriendo especial relevancia en esta última la Disposición Final Segunda LRSAL, por la que se modifica la Disposición Adicional Vigésima de la LRJPAC, no derogada expresamente y cuya aplicación genera importantes contradicciones en materia de personal ${ }^{18}$.

En segundo lugar, aquellos consorcios especiales que se exceptúan del régimen LRSAL y se rigen por lo dispuesto en sus Estatutos, respetando la normativa general y autonómica en la materia. Planteándose así el interrogante de cuál es la normativa de aplicación en todo aquello que no aborde la LRJSP o la respectiva ley autonómica.

$Y$, en tercer lugar, los consorcios adscritos a una Entidad Local a los que les será de aplicación también la LRJSP y el régimen de la LRSAL supletoriamente, aunque con carácter preferente también en aquellas Disposiciones introducidas en la LBRL que inciden en el personal al servicio de la Administración Local.

Todas estas particularidades derivadas de los criterios de adscripción del consorcio deberán ser tenidas en cuenta, en consecuencia, a la hora de abordar el régimen jurídico de este personal. Y todo ello también sin perder de vista la normativa básica específica en la materia (EBEP), la normativa de aplicación que así disponga éste (ET y demás normas convencionalmente aplicables) así como las limitaciones establecidas en la LPGE de 2018.

\section{Clases de personal}

Cualquier consorcio, como así se establece en el art. 121 LRJSP, puede contar con personal funcionario o laboral procedente de las Administraciones consorciadas. Y sólo en aquellos supuestos en que no existiera un empleado público para ejercer las funciones que el puesto de trabajo demanda, se puede contratar directamente desde el consorcio.

Ahora bien, en este punto, es preciso aclarar dos cuestiones importantes. La primera, la delimitación de qué puestos de trabajo a desarrollar en el consorcio pueden ser ocupados por personal funcionario y cuáles por personal laboral. La segunda, qué clase de funcionario o de personal laboral pueden ocupar esos puestos, es decir, ¿pueden trabajar en un consorcio los funcionarios interinos, el personal laboral de carácter temporal, ejercer funciones de confianza o asesoramiento especial el denominado personal eventual o, en el caso específico de los consorcios locales, los funcionarios de habilitación nacional?

Ambas cuestiones guardan relación entre sí y no permiten una respuesta fácil, más si cabe para el caso de los consorcios locales, si tenemos en cuenta la reforma introducida en la LRSAL en la que se deroga la Disposición Adicional Segunda del EBEP y las particularidades de los funcionarios de Administración Local que pasan nuevamente al texto de la LBRL.

$Y$ es que si bien es cierto que la delimitación de la funciones que han de ejercer los funcionarios de Administración Local del art. 92 LBRL son similares a las contenidas en el art. 9.2 EBEP para el conjunto de

18 Esta Disposición, a mi juicio, no ha sido derogada expresamente por ninguna norma. Habría que entender lo contrario si tenemos en cuenta la derogación normativa de la LRJPAC a través de la LPAC, aunque lo más correcto es que esta derogación se hubiera producido por la LRJSP que es la norma que regula propiamente el régimen jurídico del sector público. Pero la realidad es que la LRJSP no ha derogado expresamente la Disposición Final Segunda LRSAL y el art. 119.3 LRJSP atribuye además a las normas contenidas en la LBRL y la LRSAL sobre los consorcios locales el carácter de supletorio. Y como sabemos la Disposición Final Segunda LRSAL no se limita a la dimensión local de los consorcios sino que se extiende también a los autonómicos y estatales. Otra interpretación posible, a la vista de la técnica legislativa utilizada por la LRSJP, es que se quiere mantener esta Disposición exclusivamente dirigida a los consorcios locales, aunque si esa era la intención tendría que haber sido incluida esta modificación de un hipotético régimen jurídico de los consorcios locales a través de una nueva Disposición Final de la LRJSP.

No es ésta la opinión de CASTILLO BLANCO («La incidencia de la nueva Ley de Régimen...», op. cit.), para quien la LRJSP, «asimismo, y dado que en la misma hay, con carácter general, una continuidad en las soluciones ofrecidas por la Ley $27 / 2013$ y Ley $15 / 2014$, apenas supone innovación alguna del ordenamiento jurídico si dejamos a salvo algunas correcciones técnicas. Pero no nos equivoquemos que, con carácter general, no suponga una innovación destacable, no quiere decir que no haya novedades(35), a saber dos importantes de calado: respecto del régimen jurídico aplicable a los Consorcios especialmente los locales ya que la norma deroga la Ley 30/92 (art. 6.5 y DA 20), el artículo 87 LBRL, (pero no el 57 ni las DA 9. a y 12. a), el artículo 110 TRRL, los artículos $12-15$ y DA. ${ }^{2}$ 6 Ley 15/2014 y, por último, los artículos 37-40 RSCL) con lo que desaparece la exigencia preceptiva de representación proporcional, al menos en la legislación básica estatal; y, por otro lado, se aclara la posibilidad de utilizar los modos de gestión servicios públicos (art.118.3)». 
funcionarios de carrera ${ }^{19}$. No es menos cierto también que el precepto de la LBRL opta por un generalización de los funcionarios en el ámbito local, no siendo ésta la opción utilizada por el EBEP.

Los funcionarios de habilitación estatal de entonces han sido, a mi parecer, la principal motivación de la reforma LRSAL sobre el EBEP, aunque con ello se haya llevado por delante al resto de funcionarios de Administración Local. Pero creo que esta operación legislativa no era necesaria, bastaba con una modificación de la Disposición Adicional Segunda del EBEP ya sea a través de la LRSAL o ya sea, como considero más idóneo, sobre el propio texto del EBEP.

Ciertamente, me parece poco acertada la decisión desarrollada por la LRSAL y se debería contener en un mismo texto legal todas las particularidades del régimen jurídico de los empleados públicos en su sede natural, esto es, el EBEP. Y que la LBRL se centrara en todas aquellas cuestiones de organización y funcionamiento de los Entes Locales.

La situación actual no hace más que generar incertidumbre y poca certeza jurídica. En este punto, se produce una colisión entre el EBEP y la LBRL ya que conforme a los postulados del primero (art. 11 EBEP) corresponde a las leyes de desarrollo del EBEP la determinación de los criterios que delimiten los puestos de trabajo que pueden ser desarrollados por personal laboral. $Y$ ya son varias las Comunidades Autónomas las que han determinado estos criterios y que incluyen a los consorcios dentro de su ámbito de aplicación ${ }^{20}$.

La solución, a mi juicio, pasa por dar una interpretación preferente al apartado 1 del art. 92 LBRL y que todo lo no regulado en éste se regirá por «la legislación del Estado y de las Comunidades Autónomas en la materia de función pública», por mucho que se opte por una generalización de los funcionarios en las Entidades Locales ${ }^{21}$.

Y consecuentemente habrá que tener en cuenta no sólo la legislación de las Comunidades Autónomas que han desarrollado el EBEP sino también la de aquéllas que no lo han hecho y mantienen en vigor sus respectivas leyes de función pública así como la propia legislación del Estado que sigue en vigor (en todo aquello que no sea de aplicación directa del EBEP y no sea contrario a lo dispuesto en éste) ${ }^{22}$.

Desde estos planteamientos, y entrando ya en el segundo de los interrogantes planteados, es necesario precisar si más allá de los funcionarios públicos y del personal laboral, en sentido estricto, qué otras clases de empleados públicos pueden ser considerados como personal al servicio del consorcio. Me refiero concretamente a los funcionarios interinos, al personal laboral temporal, al denominado personal eventual y, específicamente para el caso de los consorcios locales, los funcionarios de habilitación nacional.

No hay duda, por lo que respecta a los funcionarios interinos, que las circunstancias legales que habilitan el desempeño de funciones propias de funcionarios de carrera, establecidas en la normativa básica de empleo público (arts. 10.1 EBEP), permiten la existencia de estos empleados públicos. Y más aun si tenemos en cuenta la dicción del apartado 6 de este precepto por el que se permite prestar los servicios que se le encomienden en la unidad administrativa en la que se produzca su nombramiento o en otras unidades administrativas en las que desempeñe funciones análogas.

El mismo planteamiento podría trasladarse al personal laboral temporal ya que las limitaciones establecidas para esta modalidad de contratación también están habilitadas expresamente en la propia LPGE de 2018, en el mismo sentido que se justifica la existencia de los funcionarios interinos, esto es, por razones excepcionales y de urgencia e inaplazables ${ }^{23}$.

En el caso del personal eventual, su presencia igualmente está permitida y no sólo en los consorcios estatales o autonómicos sino también en los de ámbito local, aunque con las limitaciones numéricas esta-

19 Si comparamos la dicción de ambos preceptos podemos comprobar que las funciones que han de ejercer los funcionarios de carrera en general y las de los funcionarios de Administración Local son similares, con la única particularidad en que el art. 92 LBRL incluye expresamente las funciones de autoridad (que también, a mi juicio, se entienden implícitas en el art. 9.2 EBEP).

20 Así las siguientes leyes autonómicas de desarrollo al EBEP contemplan a la Administración Local y a las entidades de derecho público dependientes de ésta dentro de su ámbito de aplicación: Ley 10/2010, de 9 de julio, de ordenación y gestión de la Función Pública Valenciana (art. 5); Ley 4/2011, de 10 de marzo, del Empleo Público de Castilla-La Mancha (art. 2.1); 13/2015, de 8 de abril, de Función Pública de Extremadura (art. 3.1); y, Ley 2/2015, de 29 de abril, del empleo público de Galicia (art.4.1).

21 Así conforme al art. 92.1 LBRL: «Los funcionarios al servicio de la Administración local se rigen, en lo no dispuesto en esta Ley, por la Ley 7/2007, de 12 de abril, del Estatuto Básico del Empleado Público, por la restante legislación del Estado en materia de función pública, así como por la legislación de las Comunidades Autónomas, en los términos del artículo 149.1.18. ${ }^{a}$ de la Constitución».

22 Así, a título de ejemplo podemos citar a la Ley 6/1985, de 28 de noviembre, de Ordenación de la Función Pública de la Junta de Andalucía (art. 12.2).

${ }^{23}$ Así se establece, como ya apuntamos anteriormente, en la Disposición Adicional Décima Séptima ("Contratación de personal de los consorcios del sector público") de la LPGE 2018: «No se podrá proceder a la contratación de personal temporal, excepto en casos excepcionales y para cubrir necesidades urgentes e inaplazables». 
blecidas en el art. 104 bis LBRL, como así ha declarado el Tribunal Constitucional en su Sentencia 54/2017, de 11 de mayo ${ }^{24}$. Cuestión distinta es que, como se viene apuntando doctrinalmente, las funciones que éstos desempeñan (de confianza o asesoramiento especial) deberían ser asumidas, en su día, por la figura del personal directivo profesional (art. $13 \mathrm{EBEP}$ ), cuando finalmente llegara a implantarse en nuestro país ${ }^{25}$.

En este sentido, además, no podemos perder de vista el papel que le atribuye el art. 130.3 LBRL a los funcionarios con habilitación de carácter nacional, para el desempeño de las funciones de los órganos directivos de los municipios de gran población, ni tampoco la legislación autonómica en la materia como así ha declarado la STC 103/2013, de 25 de abril ${ }^{26}$.

$Y$ es que, en efecto, de lo que se trata es de que estas funciones directivas sean asumidas por personas reclutadas mediante procesos competitivos en función de sus conocimientos, destrezas, aptitudes, habilidades y actitudes para dirigir y, con experiencia y trayectoria en la dirección de organizaciones; ya se trate de personal funcionario o laboral, o ya se trate de personas externas al ámbito de lo público, aunque no sea ésta la posición de la LBRL27.

24 Efectivamente, como también señalamos, en esta sentencia el Tribunal Constitucional declaraba inconstitucional y nulo el apartados 3 del art. 104 bis LBRL en los que se prohibía concretamente la presencia del personal eventual en los consorcios locales. Así como señala el Alto Tribunal: «los apartados 3 y 4 de ese artículo establecen, no ya topes cuantitativos, sino prohibiciones taxativas y condiciones cualitativas que inciden sobre el personal eventual de todas las corporaciones locales, incluidas las no necesarias. Por un lado, imponen que trabaje "exclusivamente en los servicios generales" de la entidad local, prohibiendo así, con carácter general, su asignación "con carácter funcional" a otros servicios o departamentos (art. 104 bis, apartado 4, LBRL). Por otro, prohíben directamente al "resto de Entidades Locales o de sus organismos dependientes", incluyendo, por tanto, a las comarcas, que cuenten con este tipo de personal (art. 104 bis, apartado 3, LBRL). Se trata de reglas que penetran de lleno en la organización interna de las corporaciones locales, estableciendo un criterio unívoco que no admite las adaptaciones que pudieran resultar del ejercicio del poder local de auto organización y de las competencias autonómicas en materia de régimen local. La prohibición de que "el resto de Entidades Locales o de sus organismos dependientes" cuente con personal eventual se inserta en un ámbito donde el alcance de la legislación básica debe ser más limitado, no solo por referirse a cuestiones de organización local, sino también por afectar a "entidades locales no necesarias o contingentes" (p. ej., comarcas). Estas entidades están dotadas de "un fuerte grado de interiorización autonómica", sin que les alcance directamente la garantía constitucional de la autonomía municipal (art. 140 CE), provincial (art. 141.2 CE) e insular (art. 141.4 CE) [STC 214/1989, FFJJ 4 b) y 15 a) y, últimamente, STC 41/2016, FJ 5]. Estos entes "entran en cuanto a su propia existencia en el ámbito de disponibilidad de las Comunidades Autónomas que dispongan de la correspondiente competencia [SSTC 214/1989, FJ 4 b), y 41/2016, FJ 5]"».

25 Efectivamente, este problema de la excesiva politización en la Administración Pública, el de marcar una línea divisoria clara para determinar dónde termina la esfera política y dónde comienza la esfera profesional, nos hace plantearnos la necesidad de delimitar los puestos de trabajo que deberían quedar enclavados en la esfera de la función directiva profesional. Por ello, considero seriamente que un primer paso para poner fin a este panorama pasa por la necesidad de reconducir la figura del empleado público eventual a su esfera natural (la estricta confianza política), sin llegar a desempeñar puestos de trabajo que han de quedar englobados en la esfera de la dirección pública profesional. A mi juicio, como ya apunté en un trabajo anterior (QUESADA LUMBRERAS, J. E., La carrera profesional en el sistema de empleo público español: modelos, análisis y propuestas, Thomson Reuters-Aranzadi, Pamplona, 2015, págs. 153 y 154), podría basarse en a los siguientes presupuestos:

1) En el ámbito de la Administración General del Estado, y en gran medida también de la Administración autonómica, los puestos de Subdirector General, Director General y Subsecretario General (o asimilados) deberían quedar englobados dentro de la dirección pública profesional, pudiendo incluso plantearse la idea de una segunda carrera constituida por esos tres escalones.

En el polo opuesto, en consecuencia, el puesto de Secretario General (o asimilado) constituiría la frontera máxima que puede estar dirigida desde el nivel político.

2) En el ámbito de la Administración Local, lógicamente, los planteamientos serían diferentes teniendo en cuenta su estructura orgánica y la heterogeneidad que presenta nuestra planta local (municipios de régimen común y municipios de gran población).

A mi parecer, lo más razonable sería que el legislador autonómico estableciera unos criterios claros en esta dirección y planteara una delimitación stricto sensu de los puestos de trabajo que quedarían englobados en la esfera de la función directiva profesional, sin llegar a agotar las amplias potestades que, en esta materia más si cabe, han de corresponder a los respectivos Gobiernos Locales.

No obstante, aunque esta es una decisión que debe corresponder a cada entidad local, sí considero que la tendencia debiera ir encaminada hacia la profesionalización de los puestos de Coordinadores Generales y Directores Generales (o asimilados).

26 La STC 103/2013, de 25 de abril, declara constitucional el art. 130.1.B, en la redacción dada al mismo por el artículo primero de la $57 / 2003$, de 16 de diciembre, de medidas para la modernización del gobierno local, siempre que se interprete de acuerdo con lo señalado en el Fundamento Jurídico 5. J), que declara: «el precepto impugnado admite una interpretación conforme con lo hasta aquí afirmado pues, en la medida en que se limita a relacionar, dentro de los órganos directivos, los titulares de órganos que pertenecen a la organización básica de los municipios de gran población, no impide a las Leyes autonómicas que completen, dentro de su competencia para regular la organización complementaria, este elenco de órganos directivos».

27 En esta línea apuntaba el art. 58. 7 del Anteproyecto de Ley básica de gobierno y Administración local (versión de 5 de febrero de 2007) que también apostaba por un modelo abierto en el que tenían cabida funcionarios y personal laboral como así establecía en su art. 58. 3: «Su designación corresponderá al Consejo de Gobierno atendiendo a criterios de competencia profesional y experiencia y mediante procedimientos que garanticen el mérito, la capacidad y la publicidad, entre funcionarios o funcionarias públicos del Grupo A y titulados o tituladas superiores, si no pertenecen a la función pública. En el acuerdo de nombramiento, que será motivado, se especificarán sus funciones y los objetivos de su gestión».

La posición del art. 130.3 LBRL, introducida por la LRSAL, difiere en este punto como se puede ver de la dicción del precepto y presenta una clara predilección por un modelo cerrado (preferentemente funcionarios públicos). 
En cuanto la posibilidad de ejercer las funciones que legalmente tiene atribuidas los funcionarios con habilitación de carácter nacional en los consorcios en que participa alguna Entidad Local, nada impediría que así fuera ${ }^{28}$. Como señala CASTILLO BLANCO: «Respecto de este tipo de funcionarios, que prestan sus servicios exclusivamente en entidades locales, ya en su momento se planteó si podían o no desempeñar necesariamente sus funciones en aquellos consorcios en que participasen entidades locales y no planteó problema alguno que, para el ejercicio de funciones reservadas a éstos (art. 92 bis LBRL), se acudiese a este tipo de funcionarios que, inclusive, podrían prestar sus servicios de forma acumulada con los de una entidad local perteneciente al Consorcio según dispusiesen los Estatutos del Ente consorciado (STS de 30 de abril de 1999, RJ. 4692). Quiere decirse que, en este tipo de funciones reservadas, los Estatutos adquieren, de nuevo, una importancia fundamental y serán éstos los que determinen la forma de prestación de esas funciones con carácter general, aunque en los que tengan carácter local en razón de la Administración a la que queden adscritos su prestación por éstos no plantea duda alguna si bien con las singularidades propias de la figura consorcial» ${ }^{29}$.

\section{Selección, provisión de puestos de trabajo y movilidad de personal}

En este punto, el régimen jurídico del personal al servicio de los consorcios es también contradictorio. Efectivamente, la LRJSP, que es la norma de preferente aplicación, no alude expresamente a la forma de provisión de los puestos de trabajo y sólo establece que procederán exclusivamente de las Administraciones participantes. Y si ello no fuera posible, se podrá contratar personal directamente por parte del consorcio, con carácter excepcional y para el ejercicio de las funciones que no se puedan cubrir.

La LRSAL, por el contrario, en la redacción que incorpora a la Disposición Adicional Vigésima de la LRJPAC, estable expresamente que el personal de los consorcios (locales, autonómicos y estatales) procederá exclusivamente de una reasignación de puestos de trabajo de las Administraciones participantes.

La interpretación más lógica a esta dicotomía, para evitar los problemas jurídicos que se derivan de la aplicación supletoria de la LRSAL, pasa por aplicar la normativa básica de empleo público ${ }^{30}$. Nuevamente,

${ }^{28}$ No es ésta, sin embargo, la posición mayoritaria entre la doctrina. A juicio de JIMÉNEZ ASENSIO (“¿ «Réquiem» por los consorcios? Notas sobre el nuevo régimen jurídico de los Consorcios tras la LRSAL”, Blog de Estudio de Consultoría Sector Público S.L.U.): «al tener los Consorcios un marcado carácter instrumental y preverse, con las excepciones que se verán, que su personal provendrá por regla general de reasignación de efectivos de las entidades que formen parte del mismo, cabría concluir que, a partir de la entrada en vigor de la LRSAL, las funciones de secretaría e intervención de tales entidades ya no deberían estar reservadas necesariamente a funcionarios con habilitación de carácter nacional, pues los Consorcios -ya claramente- no son entidades locales y se adscriben como "entidad instrumental" a una Administración matriz. Por tanto, su régimen jurídico en este punto debería ser similar al resto de entidades instrumentales del sector público local».

${ }_{29}$ CASTILLO BLANCO, F. A., "La nueva regulación de los consorcios públicos...", op. cit., págs. 917 y 918. Como explica el autor, argumentando su postura contraria a la mantenida por Jiménez Asensio (que hemos señalado anteriormente): «Desde mi punto de vista, y partiendo de que lo Estatutos juegan un papel esencial -forman parte de las peculiaridades que éstos pueden establecer-, es preciso distinguir los consorcios adscritos al sector estatal o autonómico en que nada hay que oponer a la argumentación efectuada por el citado autor bien que es cierto que, desde mi punto de vista, serían los Estatutos los que establecieran el procedimiento de provisión sin necesidad de acudir necesariamente a la reasignación de efectivos, de los que en aplicación de los criterios establecidos en la LRSAL pero también en otras normas (por ejemplo las autonómicas de régimen local), quedasen adscritos a una entidad local.

En estos últimos la situación no ha cambiado en nada por la promulgación de la LRSAL. La fijación de una naturaleza instrumental por dicha norma, que como se ha dicho, a mi juicio preexistía a esta norma no es determinante cuando lo que si parece cierto es que a esos consorcios les será de aplicación la normativa de la Administración a la que quedan adscritos y, en el caso local, la prestación de esas funciones no cabe duda que corresponde a esos funcionarios que son, además, funciones reservadas. Los Estatutos podrán establecer singularidades, en efecto, pero el régimen esencial de nuevo habrá que subrayarlo habrá de respetarse».

${ }_{30}$ Como señala asimismo CASTILLO BLANCO («La nueva regulación de los consorcios públicos...», op. cit., pág. 911): «De nuevo la más elemental lógica hubiera aconsejado, consiguiendo los mismos objetivos que parece perseguir la norma (no duplicidad de plantillas y ofrecer salida a los excedentes de personal) remitirse no a ese mecanismo excepcional sino, con carácter general, a los medios de provisión ordinarios y extraordinarios para la provisión de puestos de trabajo que existen en la legislación de empleo público y prever de forma adicional algún mecanismo para evitar esa duplicidad respecto de las Administraciones consorciadas ya que, con toda seguridad, en determinados Consorcios sobre todo aquellos de especial singularidad en cuanto a sus fines, lo más probable es que no exista en las plantillas de las Administraciones que conforman el mismo la clase de personal que se necesita de forma efectiva.

La fórmula escogida, pensada con la lógica de la supresión y reducción de plantillas propia del tiempo que vio surgir la norma, ofrece lo que ha de ser una respuesta coyuntural como solución definitiva a los procedimientos de cobertura de aquellos consorcios que, no estando incluidos en la excepción establecida en la Disposición Adicional Decimotercera en el caso del sector local y en todos los demás supuestos en el sector público autonómico y estatal, existan, se creen o presten servicios no incluidos en el artículo 26 de la LBRL. La conclusión no puede ser otra que lo que realmente se pretende es que los Consorcios que se creen o que ya existan, pero cuyo objeto no sea la prestación de servicios mínimos, tengan muy complicada su subsistencia y que, en todo caso, no produzcan en ningún supuesto duplicidad de plantillas en los mismos servicios». 
en este punto, la LRSAL vuelve a generar incertidumbre jurídica y se aleja de los planteamientos del EBEP, dejando a un lado asimismo las leyes autonómicas en desarrollo de éste que han regulado sus propios procedimientos de provisión ${ }^{31}$.

Creo sinceramente que la solución que mayor certeza jurídica plantea es la aplicación de la normativa básica de empleo público (arts. 78 a 84). Y no sólo para los funcionarios públicos sino también para el personal laboral. Y es que si bien es cierto que en materia de provisión de puestos de trabajo y movilidad del personal laboral, el EBEP se sitúa como norma subsidiaria de lo que establezcan los convenios colectivos aplicables como así establece el art. 83 del EBEP (con la excepción de la movilidad por razón de violencia de género en la que sí se establece una aplicación común para todos los empleados públicos).

No es menos cierto también que, en este punto, el EBEP se remite únicamente a los convenios colectivos que sean de aplicación y no a la legislación laboral. Planteándose así la duda interpretativa, como sostiene SALA FRANCO, «de si lo dispuesto en los arts. 39 y 40 del ET, sobre movilidad funcional y movilidad geográfica de los trabajadores, resulta no obstante de aplicación al personal laboral de las Administraciones Públicas (debido, sobre todo, a su carácter mínimo imperativo cara a la negociación colectiva) o si, por el contrario, tal como se deduce de una interpretación literal del EBEP, en caso de ausencia de regulación convencional, será de aplicación tal cual los arts. 78 a 84 del EBEP y no el ET» ${ }^{32}$.

En mi opinión, y siguiendo el criterio establecido por la propia jurisprudencia de la Audiencia Nacional cuando se han planteado dudas interpretativas sobre la aplicación preferente entre el EBEP y el ET, el conflicto tendría que resolverse atendiendo al principio de especialidad. Así, conforme a este principio, teniendo en cuenta que el EBEP es una ley especial que se aplica exclusivamente al personal laboral al servicio de la Administración Pública; tendría que tener una aplicación preferente a lo que establezca la ley general (ET) sobre este colectivo de trabajadores en esta materia (SAN 14/2008, de 6 de marzo).

Y lo que sí parece claro asimismo es que no está prohibida la contratación de personal por parte del consorcio, con carácter excepcional, para el ejercicio de las funciones que no se pueden cubrir por parte del personal de las Administraciones participantes. La aplicación preferente de la LRJSP es clara en este sentido y deja sin efecto la prohibición de la LRSAL.

\section{Cambio de adscripción y disolución del consorcio: incidencia en el personal a su servicio}

El Estatuto de los consorcios juega un papel clave a la hora de determinar el régimen jurídico de su personal cuando se produzca un cambio de adscripción del consorcio, conforme a los criterios establecidos en el art. 120 LRJSP, o incluso la propia disolución del mismo ${ }^{33}$.

El art. $121 \mathrm{LRJSP}$, en este sentido, lo único que establece es que el régimen jurídico de su personal será el de la Administración Pública de adscripción y sus retribuciones en ningún caso podrán superar las establecidas para puestos de trabajo equivalentes en aquélla. Por tanto, el interrogante fundamental giraría en torno al significado del régimen jurídico de la Administración de adscripción.

Frente a cualquier interpretación inicial que nos pudiera llevar a pensar que estamos ante una integración del personal en la Administración de adscripción, en el caso del personal funcionario, o ante una suce-

31 Así, por ejemplo, la Ley de Castilla-La Mancha no regula la reasignación de efectivos sino directamente la redistribución de efectivos, sin distinguir entre puestos de trabajo singularizados o no singularizados (a diferencia del RD 364/1995 que prevé este último tipo de puestos se realizará mediante redistribución de efectivos).

32 SALA FRANCO, T., "El personal laboral. La relación laboral de empleo público", Comentarios a la Ley del Estatuto Básico del Empleado Público, Lex Nova, Valladolid, 2007, pág. 126.

33 Como señala CASTILLO BLANCO (“La incidencia de la nueva Ley de Régimen...”, op. cit.): «los Estatutos del consorcio jugarán un papel fundamental a la hora de determinar las particularidades que, respecto de la normativa marco de general aplicación en el ámbito del sector público al que está adscrito, presentarán los consorcios en los aspectos organizativos, funcionales y financieros.

Desde mi punto de vista el régimen propio de los consorcios no puede resultar sustancialmente distinto de aquél al que está sujeta la Administración a la que quede adscrito. Así, las particularidades no autorizan a que el consorcio carezca de fiscalización, o por citar otro ejemplo tampoco autorizan a seguir procedimientos de adjudicación contractual que contraríen los establecidos para las Administraciones públicas. Autorizan, en cambio, a que se definan los órganos de fiscalización, a que se determine la composición de las mesas de contratación, a que se regule el régimen del personal que preste sus servicios en el organismo, y ello siempre que la normativa de aplicación (en este caso la normativa autonómica) no aborde una reglamentación en tal sentido que, como hemos visto, no lo hace.

En definitiva, corresponderá a los estatutos la regulación de aquellas cuestiones que, de aplicarse la normativa general y, en especial, la reglamentaria, serían de imposible cumplimiento por la falta de equiparación entre las categorías de alguna o de todas las Administraciones consorciadas con la propia Administración del consorcio». 
sión de empresas del art. $44 \mathrm{ET}$, para el caso del personal laboral ${ }^{34}$; es importante tener en cuenta un primer dato, siguiendo en este sentido la tesis de CASTILLO BLANCO.

$Y$ es que, en efecto, el art. 120.2 LRJSP determina que el consorcio quedará adscrito, en cada ejercicio presupuestario y por todo este periodo, a la Administración Pública resultante en función de los criterios de prioridad que establece. Pero una cosa debe quedar bien clara como señala el autor: «que el régimen jurídico de la Administración dominante les sea de aplicación no tiene que tener, necesariamente, esas consecuencias antes aludidas. Es decir, y por decirlo de una vez, no parece que pueda hablarse de que se produce una integración del personal funcionario al servicio del Consorcio en el empleo público de la Administración a la que queda adscrito ya que nada se dispone respecto de ello y, por demás, y en el supuesto de que se produjese de nuevo un cambio en la Administración de adscripción el resultado sería una especie de funcionario "itinerante" que sucesivamente se iría integrando en una u otra Administración a la que quedara adscrito el Consorcio».

Tampoco, y por la misma razón, «se produce una sucesión de empresas en el caso específico del personal laboral. A mi juicio no es posible una solución de tal tipo que, de otro lado, no se menciona expresamente a diferencia de lo acontecido en los supuestos de reestructuración del sector público acontecidos en los últimos tiempos» ${ }^{35}$.

Adscripción, por tanto, no significa integración y ante cualquier eventual cambio de adscripción del consorcio, el personal funcionario seguirá teniendo la condición de personal del consorcio si así fue seleccionado, en los supuestos en que no proceda de las Administraciones consorciadas; en la situación administrativa de servicio en otras Administraciones si procede de alguna de las Administraciones consorciadas (art. 88.1 EBEP) o, alternativamente, permanecerá en servicio activo en la Administración de procedencia ocupando

34 Como ha dejado establecido la jurisprudencia (véase entre otras la STSJ de Madrid de 1 de marzo de 2013, rec. 6259/2012):

«Así tenemos -como sintetizábamos en las sentencias de 14-7-2008, rec. 2089/08 y en la de 13-11-09, rec. 4324/09, de esta Sección Primera- que los distintos supuestos de subrogación empresarial, asumiendo la patronal entrante los derechos y obligaciones de la empresa saliente, se reconducen en la actualidad a los siguientes:

A) Art. 44 del ET, reformado al compás de las Directivas comunitarias e interpretación de la jurisprudencia del TJCE, condicionado al requisito subjetivo de cambio de titularidad de la empresa, centro de trabajo o unidad productiva autónoma, y al objetivo de la entrega o aporte de los elementos patrimoniales necesarios, activos materiales o inmateriales o infraestructuras básicas para la continuidad de la actividad productiva.

B) Sucesión empresarial por disponerlos los pliegos de concesiones administrativas, cumpliéndose todos y cada uno de los requisitos previstos en los mismos.

C) Subrogación empresarial convencional por así disponerlo los Convenios colectivos, aunque no exista transmisión de elementos patrimoniales, contrayéndose a los casos expresadamente pactados y en tanto se hayan cumplido todos y cada uno de los requisitos en la norma estipulada para que surta efecto, no dándose si se incumpliera alguno de ellos (SSTS 10-12-97, 9-2 y 31-3-1998, 30-9-99 y 29-1-2002).

D) Sucesión contractual mediante acuerdo entre la empresa cedente y cesionaria, aun no concurriendo los requisitos del art. 44 del ET, supuesto a que hace méritos una copiosa jurisprudencia del TS referida a las empresas de handling, (por todas STS 29-2-2000), que constituye una novación por cambio del empleador que exige el consentimiento de los trabajadores afectados en aplicación del art. 1.205 del Código.

E) Sucesión de plantillas, aun no dándose tampoco los presupuestos del art. 44 del ET ni prever la subrogación el Convenio Colectivo o el pliego de condiciones, figura esta nacida de la jurisprudencia del TJCE, por continuar la empresa entrante en la actividad, asumiendo o incorporando a su plantilla a un número significativo de trabajadores de la empresa cesante, tanto a nivel cuantitativo (asumir por ejemplo la empresa entrante dos trabajadores sobre un total de seis, STS de 25-1-2006 ), como cualitativo (STSJ de Castilla-León de 31-10-2007), siempre que la actividad productiva descanse esencialmente en la mano de obra. Aquí, la organización productiva, es la plantilla de trabajadores, entendida como un conjunto de elementos personales organizados, y constitutiva de una entidad económica que mantiene su identidad. Este supuesto ha sido aceptado por la Sala Cuarta del TS en su sentencia de 27-10-2004, (aun suscitando en la misma ciertas "reservas", entre otras razones, "por el efecto de desincentivación de estas contrataciones y del establecimiento convencional de estas garantías, que acabarán privando de las oportunidades de empleo a los trabajadores que supuestamente se quiere proteger"), ya que la doctrina establecida por el Tribunal de Justicia de las Comunidades Europeas, al resolver cuestiones prejudiciales, es vinculante para el TS que ha de acatarla y ello no sólo en el caso decidido por la sentencia que resuelve la cuestión prejudicial, sino con carácter general en todas aquellas que queden comprendidas en la interpretación que se establece».

35 CASTILLO BLANCO, F. A., "La nueva regulación de los consorcios públicos...", op. cit., págs.. 905 y 906. Pero es que aquí, como explica el autor, «no hay cambio de titularidad alguna, ni extinción del ente matriz, ni integración de éste en otro, sino simplemente asimilación de un régimen jurídico para evitar que el personal proveniente de los entes consorciados se someta a condiciones laborales distintas. Simple y llanamente eso. Lo que no quiere decir, ni mucho menos, que tal solución no presente numerosos problemas e interrogantes.

Es decir, operará el fenómeno subrogatorio del art. 44 ET si se dan los requisitos para ello, lo establece el convenio colectivo o, por lo que aquí interesa, se determinase así en las previsiones adoptadas para la reestructuración por la Ley. Pero no concurre ninguna de esas circunstancias, sino que en el caso analizado exclusivamente se establece una vis atractiva del régimen jurídico a fin de posibilitar unas mismas condiciones laborales». 
un puesto de trabajo en el consorcio (art. 86.1 EBEP). En los supuestos de disolución del consorcio habrá que tener en cuenta asimismo las garantías jurídicas contenidas en los arts. 79.4 y 88.3 EBEP ${ }^{36}$.

En el caso del personal laboral habrá que estar a lo que la normas convencionales del consorcio establezcan y, en este punto, es especialmente importante que se ofrezca una solución similar que la planteada para los funcionarios públicos; más si cabe teniendo en cuenta la posibilidad de una eventual disolución del consorcio y poder evitar así la aplicación de fórmulas extintivas de la relación de empleo, toda vez que los servicios que se prestaban en el consorcio seguirán prestándose por alguna de las Administraciones que hasta entonces estaban consorciadas. La negociación colectiva, en consecuencia, es esencial para alcanzar una asimilación de las condiciones de trabajo en estos supuestos ${ }^{37}$.

Un supuesto especial, finalmente, lo constituye los puestos reservados a funcionarios con habilitación de carácter nacional en consorcios locales creados con anterioridad a la LRSAL. En este caso, conforme la Disposición Adicional Sexta del Real Decreto 128/2018, de 16 de marzo, por el que se regula el régimen jurídico de este colectivo, estos puestos de trabajo se podrán declarar a extinguir o reclasificar en puestos de colaboración de la Entidad Local a la que se adscriban ${ }^{38}$.

\section{CONCLUSIONES}

El régimen jurídico de los consorcios ha experimentado, en los últimos años, una atención normativa sin precedentes. Su régimen orgánico, funcional, presupuestario y de gestión de personal se ha intensificado notablemente. El objetivo de las últimas reformas ha sido muy loable y comprensible tras todos estos años de crisis económica que seguimos padeciendo. Pero creo que las medidas normativas que han sido adoptadas se han cebado en exceso en torno a esta figura que no hace sino dar cumplimiento a uno de los principios más esenciales de nuestro Estado de Derecho como es el principio de cooperación entre organizaciones públicas para la satisfacción de intereses a la ciudadanía.

Pero es que, además, hay que tener en cuenta que las reformas que han sido introducidas paulatinamente (LRSAL, LRSP y LRJSP) han generado más incertidumbre que certeza jurídica, especialmente en materia de personal al servicio de los consorcios. Y todo ello sin tener en cuenta, asimismo, la incidencia de la legislación de las Comunidades Autónomas en la temática.

El resultado alcanzado, más allá de esta costumbre legislativa de refundir diferentes normas en un mismo texto, no me parece positivo. Y es que si bien es cierto que puede considerarse plausible la regulación efectuada en determinados aspectos. No es menos cierto también que en otros tantos presenta importantes contradicciones que dejan en entredicho la refundición normativa realizada por la LRJSP, y genera no pocos interrogantes que no hacen más que complicar, aún más, a los operadores jurídicos.

36 Así conforme al art. 79.4 EBEP se establece que: «En el caso de supresión o remoción de los puestos obtenidos por concurso se deberá asignar un puesto de trabajo conforme al sistema de carrera profesional propio de cada Administración Pública y con las garantías inherentes de dicho sistema».

Por su parte, el art. 88.3 EBEP viene a señalar lo siguiente: «Los funcionarios de carrera en la situación de servicio en otras Administraciones Públicas que se encuentren en dicha situación por haber obtenido un puesto de trabajo mediante los sistemas de provisión previstos en este Estatuto, se rigen por la legislación de la Administración en la que estén destinados de forma efectiva y conservan su condición de funcionario de la Administración de origen y el derecho a participar en las convocatorias para la provisión de puestos de trabajo que se efectúen por esta última. El tiempo de servicio en la Administración Pública en la que estén destinados se les computará como de servicio activo en su cuerpo o escala de origen».

37 Por lo que respecta a las situaciones del personal laboral, el art. 92 EBEP establece que la regulación a seguir será la establecida en el ET y los convenios colectivos aplicables sobre esta materia. No obstante, deja la puerta abierta a que los convenios colectivos puedan determinar la aplicación del Título VI del EBEP (situaciones administrativas de los funcionarios públicos) en lo que resulte compatible con el ET.

En este sentido, como señala SALA FRANCO (“El personal laboral...”, op. cit., págs. 126), "si se tiene en cuenta que el ET no regula precisamente verdaderas y propias situaciones del personal laboral (paralelas a las situaciones administrativas de los funcionarios públicos) sino, más bien, "situaciones suspensivas" del contrato de trabajo por una serie de causas tasadas legalmente, difícilmente se van a producir "compatibilidades" entre una y otra legislación por su falta de "homologabilidad"».

38 Así conforme al art. 15.1 del RD 128/2018: "Las Entidades Locales podrán crear otros puestos de trabajo que tengan atribuidas funciones de colaboración inmediata y auxilio a las de Secretaría, Intervención y Tesorería. Estos puestos de trabajo estarán reservados a funcionarios de Administración Local con habilitación de carácter nacional y ejercerán sus funciones bajo la dependencia funcional y jerárquica del titular de la Secretaría, Intervención o Tesorería, respectivamente». Asimismo, como establece el apartado 3 del precepto, «les corresponderá la sustitución de los titulares de los puestos de Secretaría, Intervención y Tesorería, en los casos de vacante, ausencia, enfermedad o concurrencia de causa de abstención o recusación legal o reglamentaria de los mismos». 
Un buen ejemplo de lo que vengo apuntado tiene su máximo exponente en la LRSAL, y no sólo por lo que respecta a los consorcios locales sino también a los autonómicos y estatales, especialmente en materia de personal. Y aquí se genera precisamente un problema importante. Los preceptos de la LRSAL, a pesar de su carácter supletorio en todo aquello que no aborde la LRJSP, trascienden del ámbito local. Me refiero concretamente a la Disposición Final Segunda LRSAL por la que se incluye una nueva Disposición Adicional Vigésima a la LRJPAC («Régimen jurídico de los consorcios»).

Esta Disposición, a mi juicio, no ha sido derogada expresamente por ninguna norma. Habría que entender lo contrario si tenemos en cuenta la derogación normativa de la LRJPAC a través de la LPAC, aunque lo más correcto es que esta derogación se hubiera producido por la LRJSP, que es la norma que regula propiamente el régimen jurídico del sector público.

Pero la realidad es que la LRJSP no ha derogado expresamente la Disposición Final Segunda LRSAL y el art. 119.3 LRJSP atribuye, además, a las normas contenidas en la LBRL y la LRSAL sobre los consorcios locales el carácter de supletorio. Pero como sabemos la Disposición Final Segunda LRSAL no se limita a la dimensión local de los consorcios sino que se extiende también a los autonómicos y estatales. Otra interpretación posible, a la vista de la técnica legislativa utilizada por la LRSJP, es que se quiere mantener esta Disposición exclusivamente dirigida a los consorcios locales, aunque si esa era la intención tendría que haber sido incluida esa modificación de un hipotético régimen jurídico de los consorcios locales a través de una nueva Disposición Final de la LRJSP.

En cualquier caso, creo que todo este enredo jurídico responde a la forma en que se ha venido legislando en los últimos años, que aunque era necesario responder con rapidez a los problemas económicos del país, el resultado final de los diferentes textos normativos no son los más acertados. Prueba de ello son las numerosas críticas que ha venido cosechando la LRSAL o la fórmula legislativa realizada a través de las dos nuevas leyes administrativas (LPAC y LRJSP), alejándose de las consideraciones del propio Consejo de Estado. Era previsible que, tarde o temprano, las contradicciones surgirían y con ello la inseguridad jurídica que se deriva. Y más en una materia como esta, el régimen de personal, tan desubicada en estas normas y a la que era más que previsible su poca congruencia.

Ciertamente la solución más fácil para buena parte de los interrogantes que se plantean para el personal al servicio de los consorcios sería entender derogada esta Disposición. En mi caso, y atendiendo a la realidad normativa de que no ha sido derogada expresamente, he considerado que la solución a estos problemas pasa por dar una aplicación preferente al art. 92.1 LBRL y que todo lo no regulado en ésta se regirá por «la legislación del Estado y de las Comunidades Autónomas en la materia de función pública».

Con esta interpretación pueden ser abordadas las contradicciones entre la LBRL y la LRSAL con el EBEP y con la legislación de desarrollo a éste, y se viene a dar una solución más sensata que la que nos aporta la normativa básica local, por lo que a los empleados públicos locales se refiere; evitando con ello, especialmente también, el conflictivo régimen de la Disposición Final Segunda LRSAL, por el que el personal de los consorcios ha de proceder exclusivamente de una reasignación de puestos de trabajo de las Administraciones participantes.

Creo sinceramente que la solución que mayor certeza jurídica plantea es la aplicación de la normativa básica, estatal y autonómica de empleo público. El EBEP, las leyes autonómicas en desarrollo del EBEP, pero también aquellas normas de empleo público que aun siguen en vigor, tanto a nivel estatal como autonómico. Y todo ello teniendo en cuenta, asimismo, la sobriedad de la LRJSP en esta materia. Son en estas normas, a mi juicio, en las que se debería contener todo el régimen jurídico de los empleados públicos y, sensu contrario, que la normativa básica de régimen local se centrara en todas las cuestiones de organización y funcionamiento de la Administración Local.

Habrá que esperar, en consecuencia, a si la experiencia de estos años nos hace reconducir los aciertos pero también los errores cometidos, y nos permite seguir funcionando a través de fórmulas asociativas que prestan servicios públicos a la ciudadanía, y que se siga haciendo en las condiciones más coherentes.

\section{BIBLIOGRAFÍA}

BARRERO RODRÍGUEZ, C. (2016), "Los consorcios ante un nuevo régimen jurídico", Administración de Andalucía. Revista Andaluza de Administración Pública, núm. 94, enero-abril, págs. 57-88.

BASSOLS COMA, M. (2014), "La racionalización de la Administración local en el marco de la sostenibilidad financiera: panorama general”, Cuadernos de Derecho Local, núm. 34, Fundación Democracia y Gobierno Local, Madrid, págs. 21-48. 
CASTILLO BLANCO, F. A. (2017), "La incidencia de la nueva Ley de Régimen Jurídico del Sector Público en los instrumentos de cooperación del Estado Autonómico: especial referencia a los consorcios públicos", Diario del Derecho Municipal. IUSTEL, edición de 10 de marzo de 2017.

CASTILLO BLANCO, F. A. (2014), "La nueva regulación de los consorcios públicos: interrogantes y respuestas sobre el régimen jurídico de su personal”, Revista Vasca de Administración Pública, núm. especial 99-100, mayodiciembre, págs. 887-920.

FERREIRA FERNÁNDEZ, J. (2009), "Los consorcios del sector público autonómico: naturaleza y características", Revista de Estudios de la Administración Local y Autonómica, núm. 310, pág. 169-203. DOI: https://doi. org/10.24965/reala.v0i310.9682.

GARCÍA RUBIO, F. (2015), "Los consorcios locales en el Proyecto de Ley de Régimen Jurídico del Sector Público. Reflexiones necesarias”, Documentación Administrativa. Nueva Época, núm. 2, enero-diciembre, págs. 1-17. DOI: https://doi.org/10.24965/da.v0i2.10269.

JIMÉNEZ ASENSIO, R. (2015), "El sector público local tras la Ley 40/2015: retos inmediatos y cuestiones abiertas", Blog de Estudio de Consultoría Sector Público S.L.U., edición de 17 de julio de 2015.

QUESADA LUMBRERAS, J. E. (2015), La carrera profesional en el sistema de empleo público español: modelos, análisis y propuestas, Thomson Reuters-Aranzadi, Pamplona.

SALA FRANCO, T. (2007), "El personal laboral. La relación laboral de empleo público", Comentarios a la Ley del Estatuto Básico del Empleado Público, Lex Nova, Valladolid, págs. 115-129.

TOSCANO GIL, F. (2015), "El consorcio administrativo en la encrucijada", Revista de Estudios de la Administración Local y Autonómica. Nueva Época, núm. 3, enero-junio, págs. 35-57. DOI: https://doi.org/10.24965/reala. v0i3.10239. 